\title{
MULTIPLE PR CONTROLLER-BASED METHOD FOR SUPPRESSING THE RESONANCE OSCILLATION OF TRACTION NETWORKS USING THE AUXILIARY CONVERTER OF AN ELECTRIC LOCOMOTIVE
}

\author{
MEIJUN MU, SHIHUI LIU, FEI LIN, ZHONGPING YANG \& RUNZE ZHANG \\ School of Electrical Engineering, Beijing Jiaotong University, China
}

\begin{abstract}
With the extensive application of AC drive technology, the content and times of harmonics injected into the traction network are increasingly diversified, leading to resonance accidents, especially for the harmonics of integer multiples with switching frequencies caused by AC drive technology. When the resonance occurs, the train terminal coupling over-voltage would lead to the breakdown of power supply equipment, which will affect the normal operation of the train. In order to restrain the traction network resonance, this paper analyses the resonance mechanism and proposes an improved method by using a locomotive auxiliary converter. The scheme introduces the active filter function into the fourquadrant converter control in the auxiliary power supply. Thus, in addition to the filter function, the auxiliary converter is designed to produce a compensation current by detecting the primary side current, extracting harmonic current using DFT analysis and tracking the reference current using zero-error multiple PR(M-PR) controller. Under this condition, the harmonic current value of primary side would be eliminated to almost zero and the resonance would be suppressed. The results are verified by Matlab/Simulink simulation and experiments on RT-LAB platform.

Keywords: electric locomotive, network resonance, auxiliary converter, proportional resonance, active filter.
\end{abstract}

\section{INTRODUCTION}

With the development of AC drive technology, electrical locomotives would inject diverse harmonic current into the traction network, leading to the mismatch of the train and network because of the complication of traction power supply system. Such phenomenon may bring about resonance accidents, which means equipment of the traction network would break down as train terminal voltage increasing. The harmonic frequency of resonance accidents happened recently focused on over $850 \mathrm{~Hz}$, causing the tripping of the substation, the breakdown of the roof and the ground high pressure equipment [1]-[3].

In order to avoid resonance accident, we usually adopt the way of reducing the harmonic current injected into the traction network in electrified railway. The filtering solutions include ground-based compensation and on-board compensation.

As for ground-based compensation scheme, LC filter and high pass filter can filter specific harmonics, while it is sensitive to the change of parameters and difficult to realize dynamic compensation [4]-[6]. Active filtering devices are based on power electronics technology, which can compensate harmonic current dynamically but increase cost because of the construction of the equipment [7]-[11]. For on-board compensation scheme, the effectiveness of passive filtering is unsatisfactory when the parameters change [12]. The vehicle active filter increases the volume and weight of the locomotive, which is not conducive to the light weight of the rail transit [13], [14].

However, control strategies of current loop play an important part in active filter scheme, where the commonest controllers are PI controller, predictive current controller, PR controller and so on [15]. The dynamic performance of the predictive current controller is 
better, but its accuracy depends on the accurate circuit parameters. For PI controller, it is difficult to achieve zero-error tracking for reference current. PR controller could track the reference values with no error, leading to a complete compensation of harmonic current [16]. For reference current composed by multiple harmonic current, we can use M-PR controller to track it [17], but the parameters should be designed accordingly, where methods of roots design and frequency design can be applied [18]-[20].

In view of resonance accidents caused by medium and high frequency harmonic current, an improved method for suppressing the resonance oscillation of traction network using auxiliary converter of electric locomotive is proposed in this paper. Compensation current is produced by detecting harmonic current of primary side, calculating and tracking the reference current in order to reduce the harmonic current and suppress the network resonance. That means rectification and active filter function are achieved by auxiliary four-quadrant converters (4QC) without extra circuit at the same time.

In order to realize the resonant suppression scheme in this paper, the auxiliary converter needs to generate the middle and high frequency compensation current, where the SiC devices are applied. SiC devices have characteristics of high frequency and low power loss, which has wide application prospect in vehicle converter [21].

This paper is organised as follows. Section 2 introduces the network resonance mechanism and the principle of resonance suppression. Section 3 presents control scheme including the current loop control strategy and designing of parameters for M-PR controller. Section 4 verifies this method by simulation and experiment. Section 5 gives the conclusion.

\section{RESONANCE SUPPRESSION PRINCIPLE OF THE AUXILIARY FOUR-QUADRANT CONVERTER}

\subsection{Resonance mechanism}

During the operation of the train, a certain harmonic current generated by the traction converter is injected into the traction network, which forms a resonance circuit with the impedance of the traction network, leading to the rise of train terminal voltage value, thus, resonance accident would happen.

In order to analyse the characteristics of the traction network, we usually use $\mathrm{T}$ type equivalent circuit [22].

Where $I_{T}$ is current source, equivalent model of locomotive. $Z_{\mathrm{ss}}, Z_{T n}, Y_{T n}$ are equivalent parameters of traction substation and lines. The impedance of the train ports is:

$$
Z_{q}=\frac{\frac{Z_{0}}{Y_{0}} \cosh \left(\sqrt{Z_{0} Y_{0}} l_{2}\right)\left(Z_{\mathrm{ss}} \cosh \left(\sqrt{Z_{0} Y_{0}} l_{1}\right)+Z_{c} \sinh \left(\sqrt{Z_{0} Y_{0}} l_{1}\right)\right)}{Z_{\mathrm{ss}} \sinh \left(\sqrt{Z_{0} Y_{0}} l\right)+\frac{Z_{0}}{Y_{0}} \cosh \left(\sqrt{Z_{0} Y_{0}} l\right)},
$$

where $Z_{0}, Y_{0}$ are parameters of unit length impedance and admittance.

For resonance circuit, when resonance happens,

$$
Z_{s s} \sinh \left(\sqrt{Z_{0} Y_{0}} l\right)+\frac{Z_{0}}{Y_{0}} \cosh \left(\sqrt{Z_{0} Y_{0}} l\right)=0 .
$$

At this time, the frequency is shown as follows: 


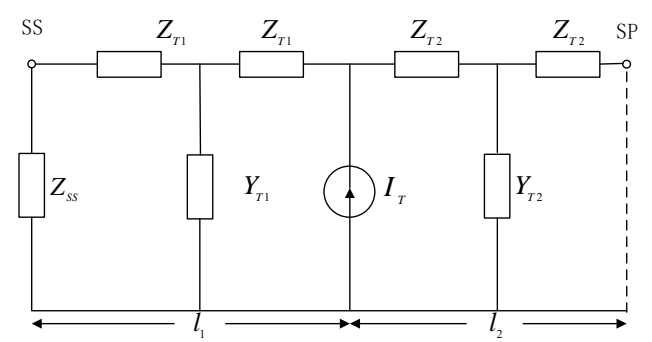

Figure 1: Traction network type T equivalent circuit.

$$
f_{h}=\frac{1}{2 \pi \sqrt{L_{s s} C}},
$$

and at the resonance frequency, $Z_{q} \rightarrow \infty$, if the frequency of injected current is equal to resonance frequency, the voltage of train terminal is $\infty$.

$$
u\left(j \omega_{h}\right)=Z_{q} \cdot i_{T}\left(j \omega_{h}\right)
$$

That means harmonic current injected into the traction network at a particular frequency will lead to the rise of voltage value, causing a resonance accident, so we consider suppressing the resonance accidents by reducing harmonic current.

\subsection{Resonance suppression principle of the auxiliary four-quadrant converter}

Block diagram of locomotive traction drive system is shown as Fig. 2(a). The primary side is connected to the traction network and the voltage is $27.5 \mathrm{kV}$. The secondary winding is associated with traction power converters and auxiliary converters. Traction power converters are composed by PWM rectifiers, DC links, traction inverters and motors. Auxiliary power supply system is connected to the auxiliary winding, providing power for the loading equipment like illumination system and air conditioner. $n_{1} 、 n_{2} 、 n_{3}$ are windings of primary winding, traction winding and auxiliary winding. $v_{p}, i_{p} 、 v_{s} 、 i_{s} 、 v_{c} 、 i_{c}$ are voltages and currents value, which are converted to the value of auxiliary side.

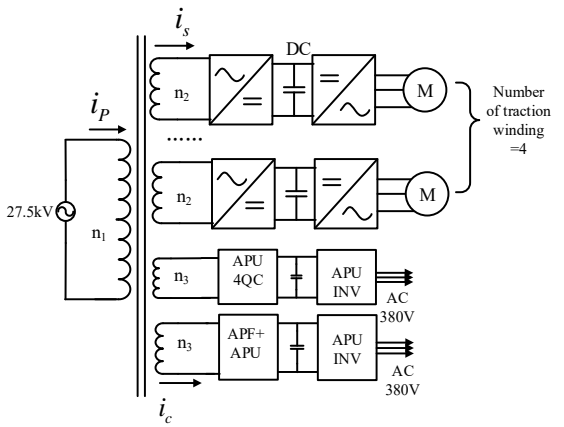

(a)

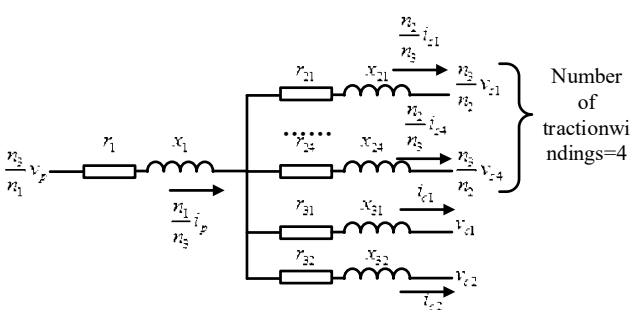

(b)

Figure 2: Block diagram of locomotive traction drive system. 
From Fig. 2(b), we can get:

$$
\begin{gathered}
\frac{n_{1}}{n_{3}} i_{p}=\frac{n_{2}}{n_{3}} \sum_{n=1}^{4} i_{s n}+\sum_{n=1}^{2} i_{c n}, \\
n_{1} i_{p}=n_{2} i_{s}+n_{3} i_{c} .
\end{gathered}
$$

As for harmonic current:

$$
n_{1} i_{p h}=n_{2} i_{s h}+n_{3} i_{c h},
$$

where $i_{s h}$ is harmonic current produced by traction converters, $i_{p h}$ is harmonic current injected into the primary side (also traction network), $i_{c h}$ is compensation current.

For the multiple harmonic current generated by traction converters, the auxiliary 4QC would produce compensation current $i_{c h}$ by detecting the harmonic current at primary side. So, $i_{p h}=0$, the harmonic current could be reduced, and resonance accidents are suppressed.

\section{RESONANCE SUPPRESSION CONTROL SCHEME}

\subsection{Circuit and principle of control strategy}

The auxiliary side current is composed by both fundamental and harmonic current, which is the same as reference current of control loop. Figs 3 and 4 shows the system block diagram of resonance suppression control method and current loop control. In this method, DC voltage controller ensures a constant output voltage. In order to obtain the fundamental reference current, the reference voltage value $U_{d} *$ would be compared with the measured one $u_{d} *$. And the reference amplitude value of the AC current $I_{c 1} *$ is generated by putting the error of voltage value into PI compensator. Then we can get the reference current $i_{c 1} *$.

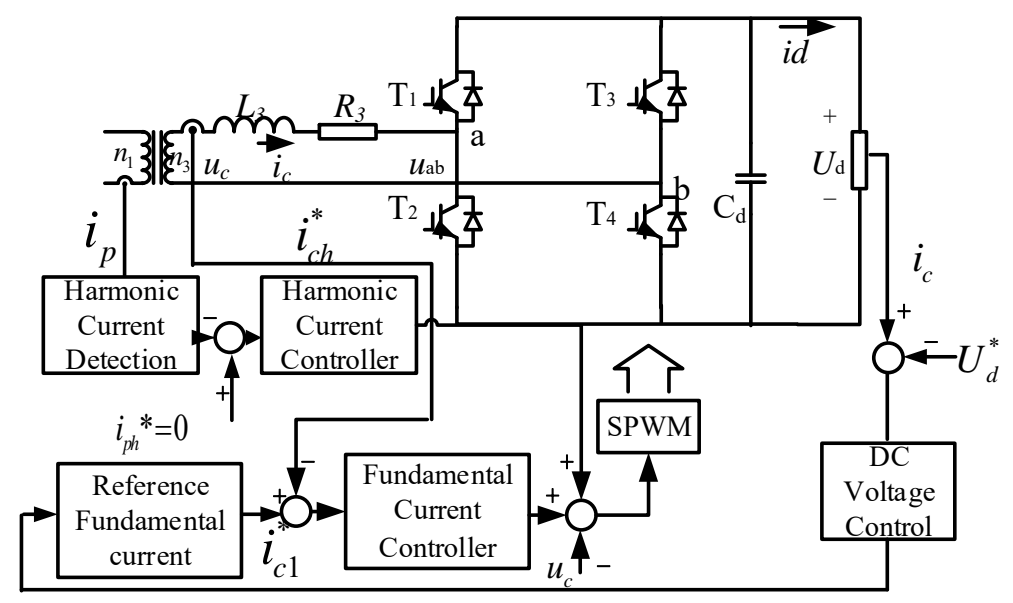

Figure 3: System block diagram of resonance suppression control method for auxiliary converter. 


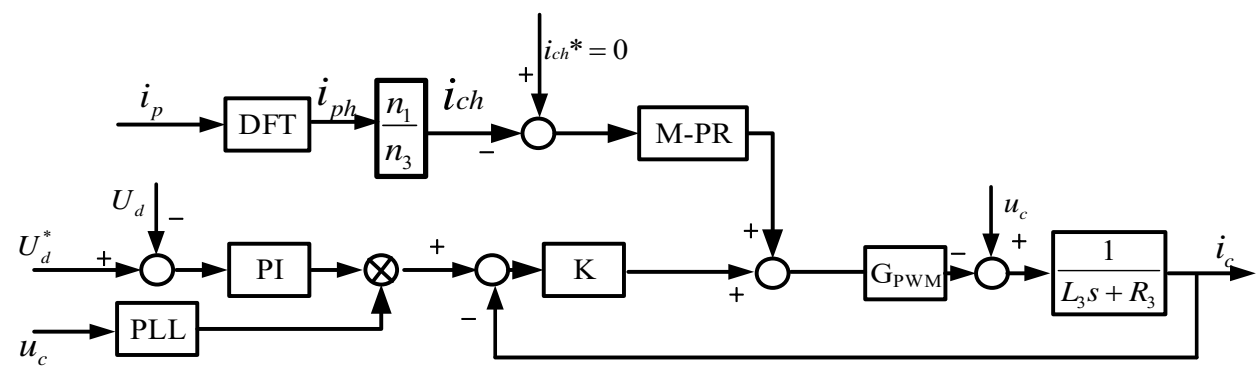

Figure 4: Current loop control block diagram.

For fundamental current controller, we use proportional controller to realize the fast tracking of the fundamental reference current. While, for harmonic current controller, M-PR controller is applied to track the reference harmonic current with no error, where the reference harmonic current of primary side $i_{c h}{ }^{*}$ is zero, $i_{p}$ is primary side current detected by current sensor, the measured harmonic current $i_{c h}$ is calculated by DFT analysis and converted to the auxiliary side by multiplying $n_{1} / n_{3}$. The error would be sent to the M-PR controller.

Modulation voltage is calculated by eqn $(8)$, where $u_{c}(\mathrm{t})$ is auxiliary side voltage, $L_{3}$ is inductance of auxiliary side, $\omega$ is fundamental angular frequency. PWM pulse is obtained by comparison of the modulation wave with the triangular carrier to control the switches, therefor, the auxiliary AC current is composed by both fundamental and harmonic current, accomplishing the function of rectification and active power filter. The harmonic current of primary side can be decreased to zero, and resonance accident could be suppressed:

$$
\left\{\begin{array}{l}
I_{N 1}=K_{p 1}\left(U_{d} *-U_{d}\right)+1 / T_{i} \int\left(U_{d} *-U_{d}\right) d t \\
I_{N 2}=I_{d} U_{d} / U_{N} \\
I_{c 1} * I_{N 1}+I_{N 2} \\
u_{a b}(t)=u_{c}(t)-\omega L_{3} I_{c 1} * \cos \omega t-K\left[I_{c 1} * \sin \omega t-i_{c 1}(t)\right]-G_{P R}(s)\left[0-i_{c h}(t)\right]
\end{array}\right.
$$

\subsection{Design of M-PR controller}

The diagram of current loop control can be simplified as Fig. 5 shows. $I_{c h}$ is input of harmonic current, $I_{c 1}$ is input of fundamental current, $I_{c}$ is output of the current loop. Eqn (9) shows the open loop transfer function, where $G_{P R}$ is M-PR controller, can be described as first order inertial link, the model of 4QC converter is shown in eqn (12).

$$
\begin{gathered}
I_{c}(s)=-\frac{G_{P R}(s) G_{P W M}(s)}{L s+R+K G_{P W M}(s)} I_{c h}(s)+\frac{K G_{P W M}(s)}{L s+R+K G_{P W M}(s)} I_{c 1}(s), \\
G_{P R}(s)=K_{p}+\sum_{h=1,3,5,7,11 \ldots} \frac{2 K_{r h} \omega_{c} s}{s^{2}+2 \omega_{c} s+\left(h \omega_{o}\right)^{2}}
\end{gathered}
$$




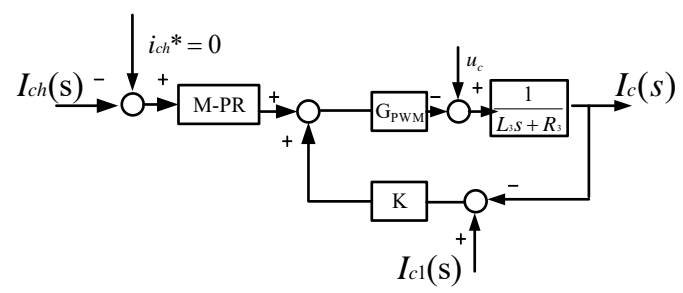

Figure 5: Current loop control block diagram.

$$
\begin{gathered}
G_{P W M}(s)=\frac{1}{T_{s} s+1}, \\
G_{i}(s)=\frac{1}{L_{3} s+R_{3}} .
\end{gathered}
$$

Open loop transfer functions of fundamental and harmonic control are shown in eqns (13) and (14), $\mathrm{K}$ is proportionality of fundamental controller. For resonant controller, $K_{p}$ is proportion parameter, $K_{r h}$ is resonance coefficient, $\mathrm{h}$ is harmonic frequency, $\omega_{0}$ is fundamental angular frequency. $\omega_{c}$ is cut-off frequency around resonant angle frequency hwo .

$$
\begin{gathered}
G_{o h}(s)=\left[K_{p}+\sum_{h=1,3,5,7,11 \ldots} \frac{2 K_{r h} \omega_{c} s}{s^{2}+2 \omega_{c} s+\left(h \omega_{o}\right)^{2}}\right] \frac{1}{T_{s} L_{3} s^{2}+L_{3} s+K}, \\
G_{o 1}(s)=\frac{K}{T_{s} L_{3} s^{2}+L_{3} s+K}
\end{gathered}
$$

In the equations, $\mathrm{L}_{3}=50 \mu \mathrm{H}$, switching frequency fs $=20 \mathrm{kHz}$.

When designing the parameters, proportionality of fundamental controller is designed firstly. With the increase of $\mathrm{K}$, the cut-off frequency and bandwidth would increase, the response speed will be faster. On the other hand, phase margin is lower, which means the stability would be influenced. In order to ensure that the system has a faster corresponding speed and good stability, the value of $\mathrm{K}$ is 2 .

For parameters of harmonic controller, we have to design the proportionality coefficient $\mathrm{Kp}$, which determines the response speed and stability of the system. Then, resonance coefficient $\mathrm{Kr}$ and cut-off angular frequency $\omega_{\mathrm{c}}$ are chosen. In this paper, 3rd, 17th, 31st order harmonic current is injected into the network, which means the resonance frequency is chosen as mentioned above.

As shown in Fig. 6(b), with Kp increases, the response speed is getting higher while the system is destabilized. In order to obtained the phase margin between $30^{\circ}-60^{\circ}$, and a fast response speed, the Kp value is 5 .

$K_{r h}$ determines the gain at the resonance frequency, as shown in Fig. 7(a), with the increase of $K_{r h}$, the gain would be higher, which means it has a good performance in tracking the reference current. While the phase margin is lower, leading to the instability of the system. 


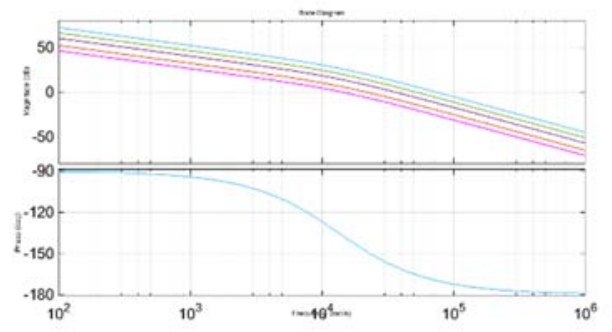

(a)

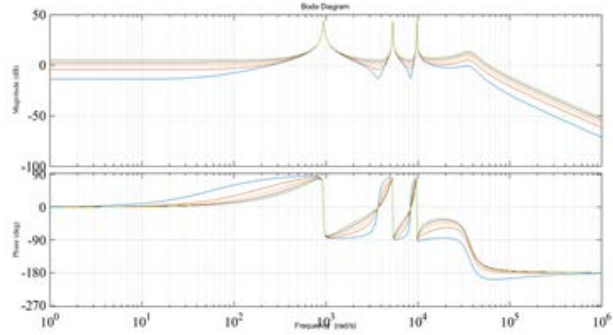

(b)

Figure 6: (a) The influence of proportionality coefficient of fundamental controller K; (b) The influence of proportionality coefficient of harmonic controller Kp.

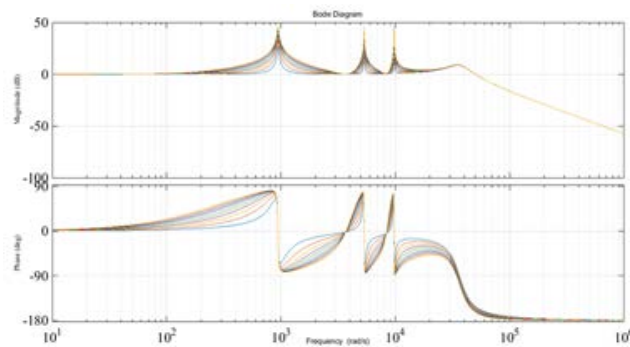

(a)

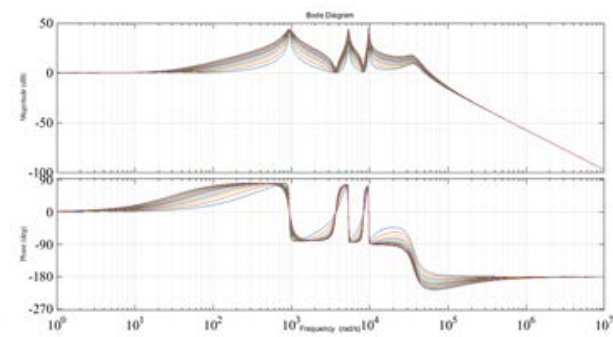

(b)

Figure 7: (a) The influence of resonance coefficient Kr; (b) Influence of cut-off frequency.

Considering both the stability and response speed, we design the values as follows: $K_{r 3}=500, K_{r 17}=200, K_{r 31}=100$.

$\omega_{\text {ch }}$ is cut-off frequency around resonance frequency, and decides the sensitiveness to the frequency offset, which prevents detuning. According to GB/T15945-2008, offset frequency of power system is no more than $0.2 \mathrm{~Hz}$, for h-order harmonic current, offset frequency $<(0.2 \times \mathrm{h}) \mathrm{Hz}$.

According to the definition of bandwidth, we get the equation:

$$
\left|\frac{2 K_{r h} \omega_{c h}(j \omega)}{(j \omega)^{2}+2 \omega_{c h}(j \omega)+\omega_{o}^{2}}\right|=\frac{K_{r h}}{\sqrt{2}} \text {. }
$$

At this time, the bandwidth is $\omega_{c h} / \pi$, so:

$$
\omega_{c h} / \pi \geq 2 \times 0.2 \times h H z .
$$

From Fig. 7(b), we can see that with the increase of $\omega_{\text {ch }}$, the bandwidth is wider around the resonance frequency, the sensitivity to frequency offset is reduced. But the stability is influenced. So the value of cut-off frequency: $\omega_{\mathrm{c} 3}=3.6, \omega_{\mathrm{c} 17}=20.4, \omega_{\mathrm{c} 31}=37.2$. 


\section{SIMULATION AND EXPERIMENTAL VALIDATION}

In this paper, we do simulations on Matlab/simulin to verify the effectiveness of this control scheme.

The equivalent model of a certain traction network is established, and the impedance analysis is shown in Fig. 8. And the impedance is high at $1550 \mathrm{~Hz}$.

The block diagram of the locomotive system is shown in Fig. 2, the switching frequency of the traction converter is $450 \mathrm{~Hz}$, the auxiliary converter switching frequency is $20 \mathrm{kHz}$. Main circuit parameters are listed in Table 1.

If there is no resonant suppression function applied in the auxiliary 4-QC, the frequency spectrum analysis of the primary side current is shown in Fig. 9.

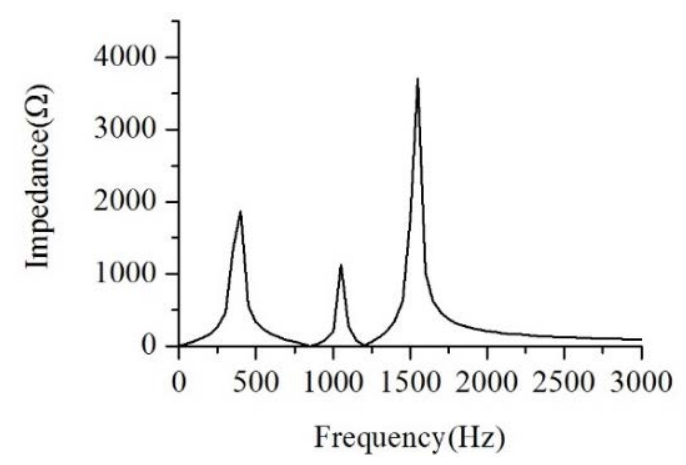

Figure 8: Impedance characteristic of a line.

Table 1: Main circuit parameter.

\begin{tabular}{|l|l|l|l|}
\hline Windings & $\begin{array}{l}\text { Primary } \\
\text { side }\end{array}$ & $\begin{array}{l}\text { Traction } \\
\text { side }\end{array}$ & $\begin{array}{l}\text { Auxiliary } \\
\text { side }\end{array}$ \\
\hline Rated power & $7051 \mathrm{kVA}$ & $6400 \mathrm{kVA}$ & $2 \times 217 \mathrm{kVA}$ \\
\hline Rated voltage & $25 \mathrm{kV}$ & $4 \times 1950 \mathrm{~V}$ & $2 \times 304 \mathrm{~V}$ \\
\hline Rated current & $282 \mathrm{~A}$ & $4 \times 820 \mathrm{~A}$ & $2 \times 714 \mathrm{~A}$ \\
\hline
\end{tabular}

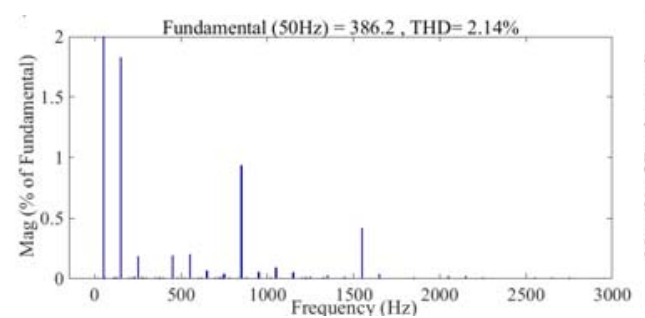

(a)

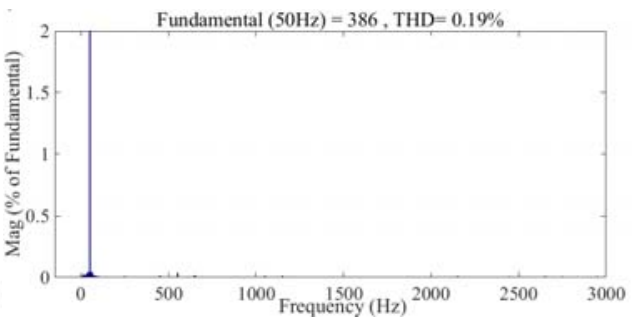

(b)

Figure 9: (a) Primary current spectrum before compensation; (b) Primary current spectrum after compensation. 
After the resonant suppression function is applied, the THD of the primary side is decreased from $2.14 \%$ to $0.2 \%$, the harmonic contents at $150 \mathrm{~Hz}, 850 \mathrm{~Hz}, 1550 \mathrm{~Hz}$ are reduced to almost 0 , and the resonance is suppressed. At this time, the peak value of the train terminal voltage decreases to a normal value. Fig. 10 shows the voltage waveform of traction network; the resonance is suppressed after $3 \mathrm{~s}$.

In order to verify the feasibility of the control algorithm, we carry out the experiment on RT-LAB platform, which is composed by DSP controller, PC and OP5600 simulator. DSP controller is applied for programming, PC is used to build the model by OPAL-RT software and debug the program by CCS6.0, and we can download the model into OP5600 to realise the hardware-in-the-loop simulation. The picture of platform is shown in Fig. 11.

In the experiment, because of the limitation of the calculation precision, the switching frequency is chosen as $5 \mathrm{kHz}$ to verify the feasibility of the control scheme, and the effectiveness of rectification function is verified.

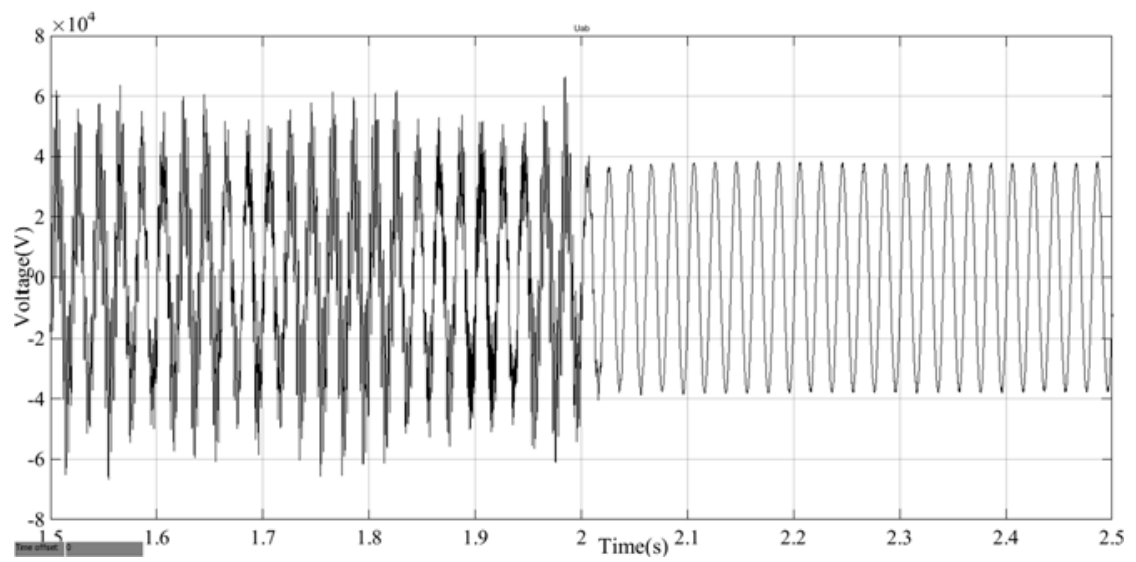

Figure 10: Voltage waveform of traction network.

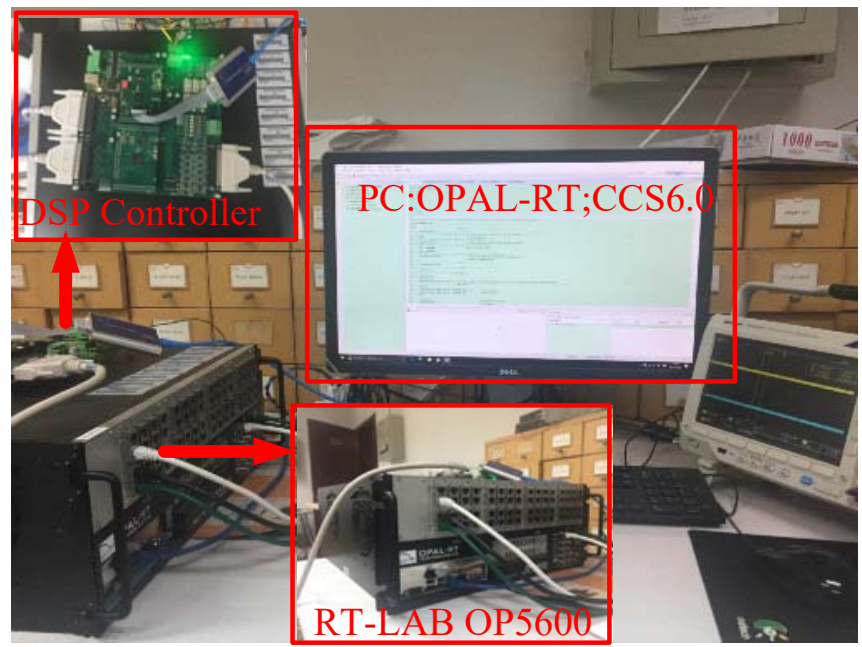

Figure 11: RT-LAB experimental platform. 
When the harmonic current of $3.6 \mathrm{~A}, 850 \mathrm{~Hz}$ is injected into the traction side, the waveforms of primary side current are shown in Fig. 12 and their spectrums are shown in Fig. 13.

From the experimental experiments, we can see that the THD is decreased from $0.96 \%$ to $0.49 \%$, which means auxiliary $4 \mathrm{QC}$ harmonic suppression control algorithm can restrain the harmonics generated by the traction side.

Fig. 14 is the output voltage waveform of the auxiliary 4QC. The function has little effect on the rectifier function, which can maintain the voltage output of the DC side at the value of $600 \mathrm{~V}$ and supply power to the auxiliary equipment.

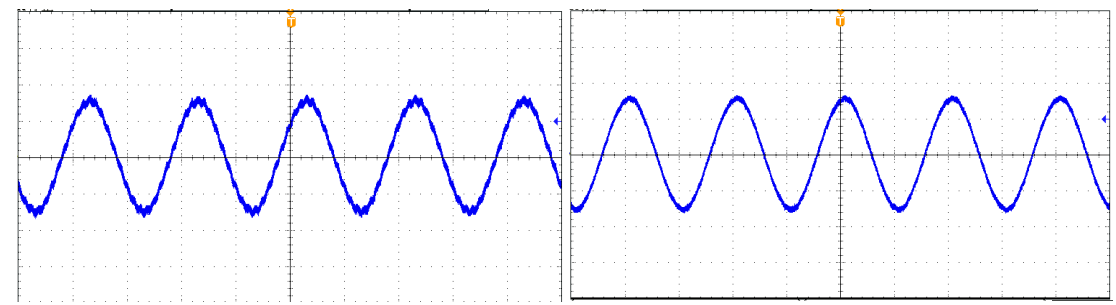

(a)

(b)

Figure 12: (a) Waveform of primary side current before compensation; (b) Waveform of primary side current after compensation.

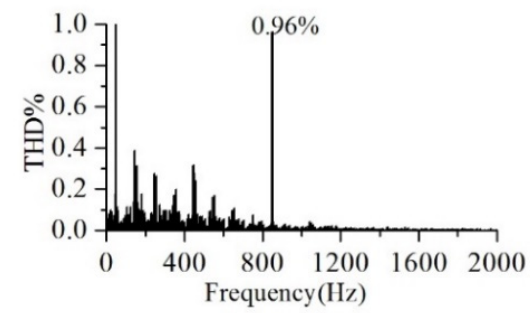

(a)

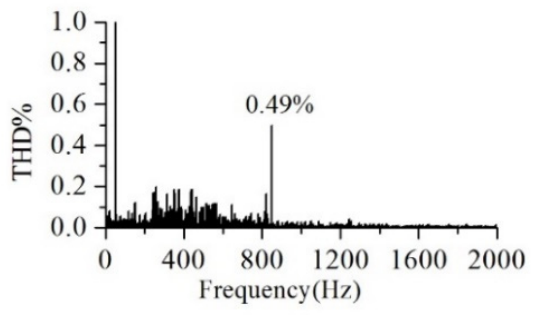

(b)

Figure 13: (a) Spectrum of primary side current before compensation; (b) Spectrum of primary side current after compensation.

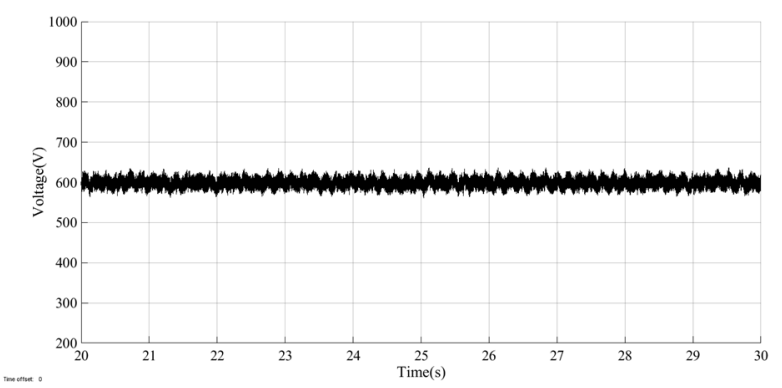

Figure 14: DC side output voltage of auxiliary converter. 


\section{CONCLUSION}

Aiming at the harmonic generated by electric locomotive traction converter and cause the resonance accident, an improved method for suppressing the resonance oscillation of traction network using auxiliary converter of electric locomotive is proposed.

This paper analyses the principle of resonance and comes to the conclusion that resonance voltage can be suppressed by reducing the harmonic current at some certain frequency. In order to produce the compensation current, M-PR controller is applied in auxiliary 4-QC, and the parameters are designed according to the stability and response speed of the system. As a result, the auxiliary converter completes the rectification function while reducing the harmonic current of the primary side to zero without additional hardware circuits. It is insensitive to the variation of frequency and can realize the dynamic compensation of the harmonic currents and suppress the network resonance. The effectiveness of this control strategy is verified both by simulation and experiment. SiC devices are applied in the auxiliary 4-QC to generate the high-frequency compensation current.

\section{REFERENCES}

[1] Song, K. et al., Windowed SHE-PWM of interleaved four-quadrant converters for resonance suppression in traction power supply systems. IEEE Transactions on Power Electronics, (99), p. 1, 2017.

[2] Liu, J., Resonance mechanism between traction drive system of high-speed train and traction network. Transactions of China Electrotechnical Society, 28(4), pp. 221-227, 2013.

[3] Cui, H. et al., Simulation study of the harmonic resonance characteristics of the coupling system with a traction network and AC-DC-AC trains. Proceedings of the CSEE, 34(16), pp. 2736-2745, 2014.

[4] Hu, H., He, Z. \& Gao, S., passive filter design for china high-speed railway with considering harmonic resonance and characteristic harmonics. IEEE Transactions on Power Delivery, 30(1), pp. 505-514, 2015.

[5] Vaclav, K. \& Bohumil, S., Effect of filter and compensation unit in the traction power supply at extreme distortion. International Conference on Compatibility and Power Electronics, IEEE, pp. 7-12, 2013.

[6] Zihan, L. \& Yuanzhe, Z., Study on a new type of high pass high pass filter for high speed electrified railway. Electric Railway, (1), pp. 13 - 17, 2014.

[7] Kwon, K.M., Song, Y.S. \& Choi, J., 6MVA single-phase APF for high speed train line in Korea. International Conference on Power Engineering and Renewable Energy, IEEE, pp. 31-36, 2015.

[8] Bueno, A. et al., Harmonic and unbalance compensation based on direct power control for electric railway systems. IEEE Transactions on Power Electronics, 28(12), pp. 5823-5831, 2013.

[9] Yue, W. et al., Study on hybrid power filter used in electrified railway system. Proceedings of the CSEE, 2003.

[10] $\mathrm{Wu}, \mathrm{L}$. et al., Cascaded H-bridge active power filter applied to electrified railway system. Tiedao Xuebao/Journal of the China Railway Society, 39(5), pp. 33-39, 2017.

[11] Li, J.L. et al., Cascade H-bridge converter with carrier phase shifted SPWM technique and its application in active power filter. Proceedings of the CSEE, 26(10), pp. 109113, 2006.

[12] Tang, J. et al., Development of locomotive passive compensation controller based on SoC and CPLD platform. Electric Drive for Locomotives, 2006. 
[13] Maeda, T. et al., A hybrid single-phase power active filter for high order harmonics compensation in converter-fed high speed trains. Power Conversion Conference Nagaoka 1997. Proceedings of the IEEE, 2, pp. 711-717, 2002.

[14] Li, H. et al., Active power decoupling for high-power single-phase PWM rectifiers. IEEE Transactions on Power Electronics, 28(3), pp. 1308-1319, 2013.

[15] Gao, J., Lin, F. \& Zheng, T.Q., Proportional-resonant control of single-phase PWM rectifiers based on grid voltage prediction. Transactions of China Electrotechnical Society, 26(5), pp. 45-51, 2011.

[16] Luo, A. et al., An improved reactive current detection and power control method for single-phase photovoltaic grid-connected DG system. IEEE Transactions on Energy Conversion, 28(4), pp. 823-831, 2013.

[17] Gao, J.L. et al., Research on harmonic current elimination method of single-phase PWM rectifiers. Proceedings of the CSEE, 30(21), pp. 32-39, 2010.

[18] Wang, J., Zheng, T.Q. \& Gao, J., Design of current proportional-resonant regulator for single-phase PWM rectifier based on root-locus method. Transactions of China Electrotechnical Society, 27(9), pp. 251-256, 2012.

[19] Yang, J. et al., A current control method for LCL active power filters based on the reduced order generalized integrator. Proceedings of the CSEE, 2017.

[20] Han, D., Li, Y. \& Sarlioglu, B., Analysis of SiC based power electronic inverters for high speed machines. IEEE Applied Power Electronics Conference and Exposition (APEC), Charlotte, NC, pp. 304-310, 2015.

[21] Shamsi, P., McDonough, M. \& Fahimi, B., Wide-bandgap Semiconductor technology: its impact on the electrification of the transportation industry. IEEE Electrification Magazine, 1(2), pp. 59-63, Dec. 2013.

[22] Chu, X. et al., Analysis of high frequency resonances in the power supply line of the high speed train. Transactions of China Electrotechnical Society, 28(2), pp. 354-359, 2013. 